\title{
Colonisation of the eastern Mediterranean by Red Sea cumaceans, with the description of a new species
}

\author{
JORDI CORBERA ${ }^{1}$ and BELLA S. GALIL ${ }^{2}$ \\ ${ }^{1}$ Carrer Gran, 90, 08310 Argentona, Catalonia, Spain. E-mail: corbera@sct.ictnet.es \\ ${ }^{2}$ National Institute of Oceanography, Israel Oceanographical \& Limnological Research, Haifa, Israel.
}

\begin{abstract}
SUMMARY: In samples collected in the course of the national monitoring programme, two interesting cumacean species were collected on the shallow bottoms (6-14 m) of Haifa Bay, Israel. Scherocumella gurneyi, previously known from the Red Sea and the Suez Canal, is recorded for the first time in the Mediterranean Sea. Eocuma rosae is described as a species new to science. Diagnostic characters such as its flattened carapace bearing a sharp marginal carina, the pair of anteriorlycurved acute horns and the pair of dorsal carinae, place E. rosae with other species of the same genus known from the IndoPacific Ocean. It is suggested it entered the Mediterranean through the Suez Canal.
\end{abstract}

Keywords: Cumacea, Scherocumella, Eocuma, new species, alien, Erythrean invaders, Red Sea, Mediterranean.

RESUMEN: COLONIZACIÓN DEL MEDITERRÁNEO ORIENTAL POR CUMÁCEOS DEL MAR ROJO, CON LA DESCRIPCIÓN DE UNA NUEVA ESPECIE. - En muestras obtenidas en el curso del programa nacional de seguimiento, se recolectaron dos especies interesantes de cumáceos en los fondos superficiales de la bahía de Haifa, Israel. Scherocumella gurneyi, una especie previamente conocida del mar Rojo y del Canal de Suez, se cita por primera vez en el Mediterráneo. Eocuma rosae se describe como una nueva especie para la ciencia. Sus carácteres diagnósticos, tales como su caparazón aplanado con una marcada carena lateral, el par de dientes dirigidos hacia adelante y el par de carenas dorsales, situan a esta especie junto con otras del mismo género conocidas del Indo-Pacífico. Se sugiere que E. rosae entró en el Mediterréneo por el Canal de Suez.

Palabras clave: Cumacea, Scherocumella, Eocuma, nueva especie, especies exóticas, invasores eritreos, Mar Rojo, Mediterráneo.

\section{INTRODUCTION}

The composition of the Mediterranean nearshore biota has been profoundly affected by anthropogenic invasions of alien species (Zibrowius, 1992). Shipping and mariculture have contributed a great number of alien species, but the opening of the Suez Canal in 1869 allowed a veritable caravan of over 300 Erythrean and IndoPacific species to enter the Mediterranean Sea (Galil, 2000). These aliens have caused significant ecological and economic impacts in the easternmost Mediterranean (Goren and Galil, 2005). The continuing influx of alien biota, and the concurrent adverse changes in the native communities, are part of a catastrophic anthropogenic ecosystem shift that threatens the sea.

The present paper describes two Red Sea cumaceans recorded from the Mediterranean Sea: Scherocumella gurneyi (Calman, 1927), known from the Red Sea and Suez Canal, and a species new to science belonging to the genus Eocuma.

\section{MATERIAL AND METHODS}

The specimens were collected in Haifa Bay in the course of the national monitoring programme of 

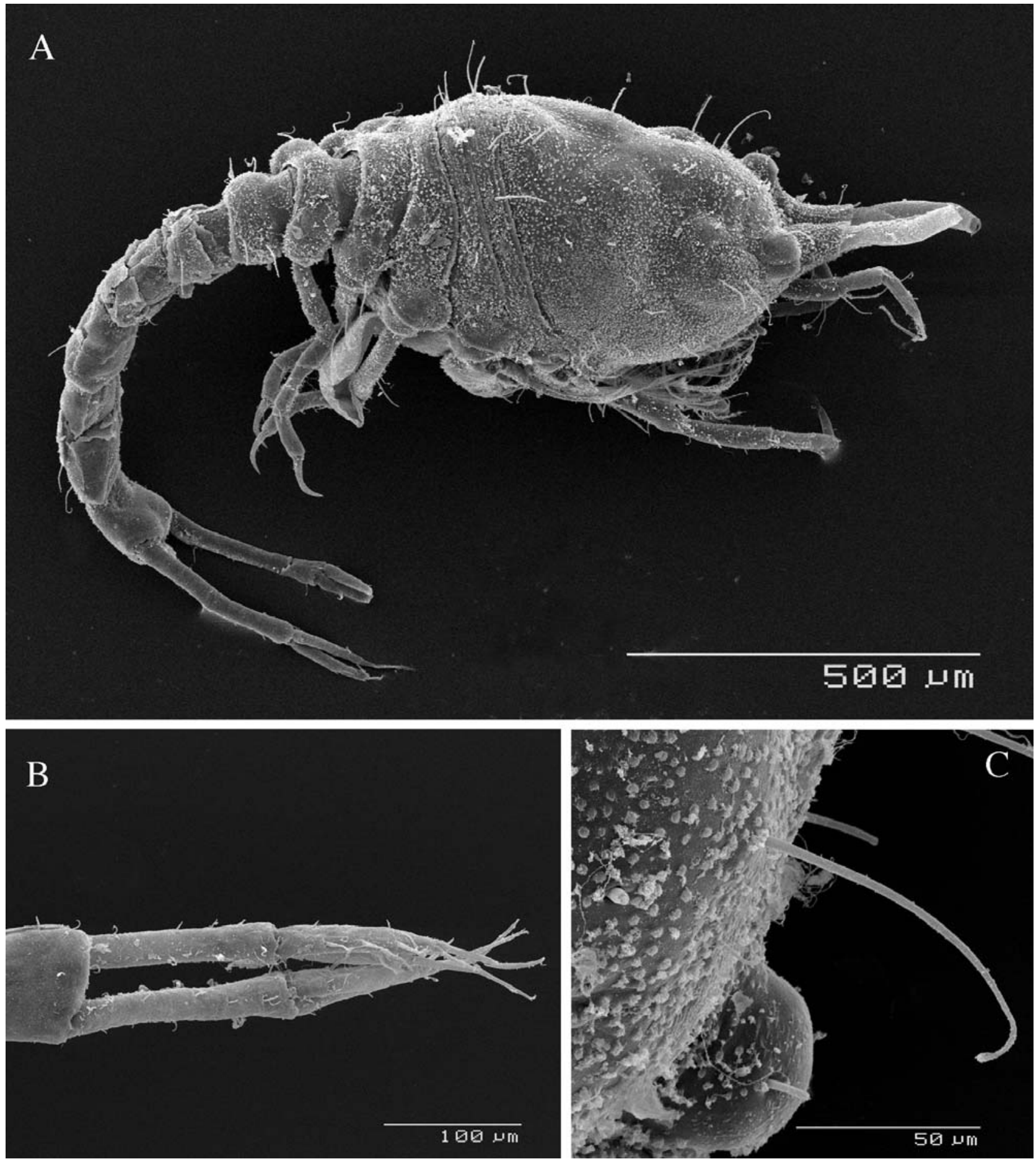

Fig. 1. - Scherocumella gurneyi (Calman, 1927), female, SEM photographs: A, whole animal in lateral view; B, uropods; C, microstructure of the carapace cuticle near the eye showing microtubercles and a long simple seta.

the Mediterranean coast of Israel. Sediment samples were collected using a Van Veen grab $\left(0.08 \mathrm{~m}^{2}\right)$ and preserved in $10 \%$ formaldehyde. The sediment was sieved on $0.25 \mathrm{~mm}$ mesh, preserved in $70 \%$ ethanol, and sorted. The specimens were dissected in lactic acid and stained with Chlorazol black. Material pre- served in permanent glass slides was mounted in Fauré medium sealed with nail varnish. Drawings were prepared using a camera lucida mounted on an Olympus microscope. A few specimens of both species were examined with a Hitachi H-2300 scanning electron microscope; they were prepared by 
dehydration through graded ethanol, critical point dried, mounted on stubs and sputter-coated with gold. The terminology follows Bacescu and Petrescu (1999). The specimens were deposited in the National Zoological Collections, Tel Aviv University (TAU) and the cumacean collection of the Institut de Ciències del Mar (CSIC), Barcelona (ICM).

\section{RESULTS}

Order Cumacea Kröyer, 1846

Family NANNASTACIDAE Bate, 1866

Scherocumella gurneyi (Calman, 1927)

(Fig. 1)

Nannastacus gurneyi Calman, 1927: 400-401, fig. 101. Bacescu and Muradian, 1975: 47-51, fig. 7.

Scherocumella gurneyi Watling, 1991: 754.

Material examined: Haifa Bay, Israel. National Monitoring: stn H27B, 32 $49.82^{\prime} \mathrm{N} 35^{\circ} 01.27^{\prime} \mathrm{E}, 14 \mathrm{~m}$ depth, 17.08.2005, 2 adult females, 1 preadult female, 2 adult males, 2 preadult males, 2 mancas (ICMU 121/2006); stn H27C, $32^{\circ} 49.2^{\prime} \mathrm{N} 35^{\circ} 01.27^{\prime} \mathrm{E}, 14 \mathrm{~m}$ depth, 17.08.2005, 2 adult females, 4 preadult females, 3 adult males, 5 preadult males (TAU AR27821).

Remarks. The genus Scherocumella was erected by Watling (1991) to accommodate species previously included in the genus Nannastacus Bate, 1865 possessing anteriorly united elongate pseudorostral lobes, acute or subacute, but not projecting, anterolateral angle in female, and uropod peduncle longer than pleonite 6 . Of the 16 species currently assigned to the genus, only S. longirostris (Sars, 1879), the type species, is known from the Mediterranean Sea; the other species are distributed in the Indo-Pacific Ocean and the Red Sea. S. gurneyi differs from $S$. longirostris in the relative length of the pseudorostral lobes, which are longer than a third of carapace length in S. longirostris and shorter than a quarter in S. gurneyi (Fig, 1A). Moreover, integument is covered by a lot of very small denticulate tubercles and some long simple setae (Fig. 1C) that seem to be absent in S. longirostris (pers. obser.).

\section{Family BoDOTRIIDAE Scott, 1901 \\ Eocuma rosae n. $\mathrm{sp}$.}

(Figs. 2-4)

Type material: Haifa Bay, Israel. Holotype: stn H23, 3249.89'N $35^{\circ} 02.71^{\prime} \mathrm{E}, 6 \mathrm{~m}$ depth, $17.08 .2005,1$ adult female (TAU AR27822). Paratypes: stn H27C, 32 49.82'N 3501.27'E, $14 \mathrm{~m}$ depth, 17.08.2005, 2 preadult females (one of them dissected in two slides), 2 juveniles, 1 manca (ICMU 122/2006); stn H27A, $32^{\circ} 49.82^{\prime} \mathrm{N} 35^{\circ} 01.27^{\prime} \mathrm{E}, 14 \mathrm{~m}$ depth, $17.08 .2005,4$ preadult females, 2 juveniles (TAU AR27823); stn H27B, 32 $49.82^{\prime} \mathrm{N}$ $35^{\circ} 01.27^{\prime} \mathrm{E}, 14 \mathrm{~m}$ depth, 17.08.2005, 1 preadult female, 1 juvenile, 1 manca (ICMU 123/2006).

Etymology. This species is named in memory of Rosa Benedicto, mother of the first author, recently deceased after a long illness.

Diagnosis. Carapace flattened with a sharp marginal carina bearing a pair of anteriorly curved acute horns, with a pair of dorsal carinae running more or less parallel to the middorsal line from the suture of the frontal lobe to nearly the posterior margin of the carapace. Eye-lobe rounded, without lenses.

Description. Adult female, $4.25 \mathrm{~mm}$ total length. Carapace (Figs. 2A-B, 3A) as long as $1 / 3$ total length, 1.45 times as long as wide, flattened with a sharp marginal carina bearing a pair of acute anteriorly curved horns; dorsal median carina extending from eye-lobe to the posterior margin of carapace; a pair of dorsolateral carinae running more or less parallel to the mid-dorsal line, from the suture of the frontal lobe to nearly the posterior margin of carapace. Integument full of apparently sensory structures (Fig. 3B, C). In dorsal view the lateral margins more or less parallel from lateral horns to posterior margin (in preadult females maximum carapace width is on lateral horns and decrease progressively backward). Eye-lobe rounded, lacking lenses.

Antennule peduncle triarticulate, article 1 flattened, broader at base; article 3 longer than article 2; main flagellum biarticulate, very short, with 2 aesthetascs distally; accessory flagellum rudimentary (Fig. 2C). Mandible (Fig. 2D) with 10 setae between pars incisiva and pars molaris. Maxillule (Fig. 2E), inner endite with four acuminate and one serrate setae; palp with two long filaments. Maxilla (Fig. $2 \mathrm{~F}$ ), endites not exceeding the protopod, with simple and serrate setae. Maxilliped 1 (Fig. 2G), basis produced distally and with five plumose setae on inner margin; carpus with seven flattened setae on inner margin. Maxilliped 2 (Fig. 4A), basis slightly shorter than the rest of appendage, with two long plumose setae on distal inner corner; carpus longer than merus, with plumose setae on inner margin; propodus with simple setae on inner margin, a long plumose seta on external face and a long seta on distal outer corner. Maxilliped 3 (Fig. 4B), basis short, as long as the combined length of the following 


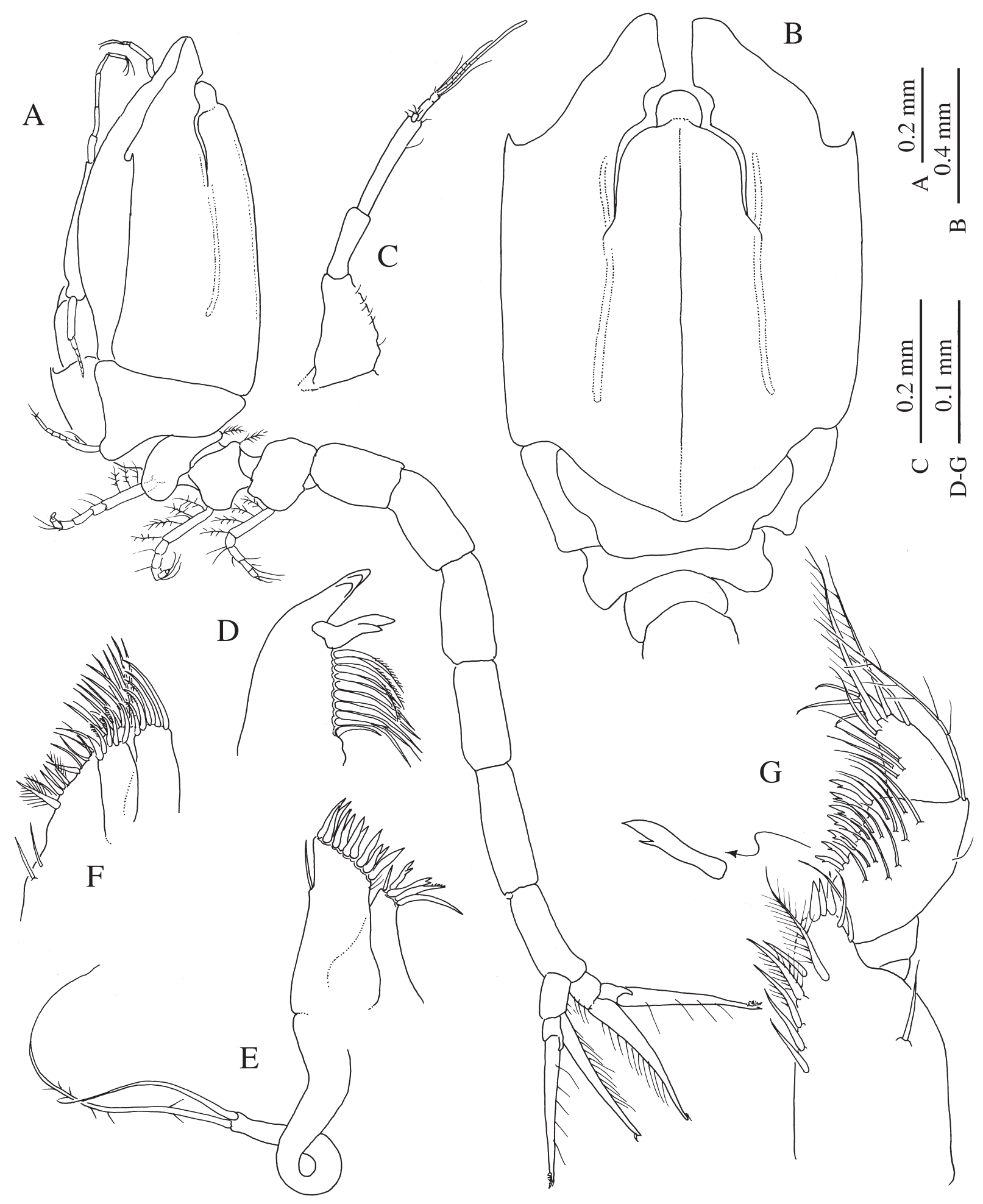

Fig. 2. - Eocuma rosae sp. nov., adult female, holotype: A, whole animal in lateral view; B, dorsal view of the carapace and last four thoracic segments. Preadult female, paratype: C, antenna 1; D, left mandible; E, maxillule; F, maxilla; G, maxilliped 1.

three segments, distal part produced into a long, narrow, curved process reaching beyond the merocarpal articulation; process with a row of plumose setae on inner margin and two on its tip; ischium longer than merus, with five plumose setae and a simple one on inner margin; merus produced distal- 
ly; carpus, propodus and dactylus of similar length. Pereopod 1 (Fig. 4C), basis as long as the combined length of the four following segments, produced distally into a pointed process, which has a long plumose seta on the tip; carpus slightly longer than propodus, and 1.5 times as long as dactylus. Pereopod 2 (Fig. 4D) longer than basis of pereopod 3 , basis shorter than the remaining segments, ischium fused with the basis, merus with a distal acuminate setae reaching half length of propodus. Pereopod 3 and 4 similar (Fig. 4E, F), basis slightly shorter than rest of appendage with plumose setae on margins and one simple seta on distal corner; merus longer than carpus; carpus with two long simple setae on distal corner; dactylus shorter than half propodus length, with a long distal seta. Pereopod 5 (Fig. 4G), basis as long as rest of appendage; merus longer than carpus; carpus with two long simple setae on distal corner; dactylus shorter than half propodus length.

Uropod peduncle with three plumose setae on inner margin (Fig. 4H), shorter than half length of rami. Both rami of the same length; endopod with 12 long plumose and three short acuminate setae on inner margin, its tip with a setulate seta; exopod biarticulate with five plumose setae on inner margin of the article 2, its tip with two curved setulate setae (Fig. 3D).

Remarks. Day's (1978) key of the genus Eocuma has three species having the entire lateral margin of the carapace carinate, a pair of lateral horns and a pair of dorsolateral carinae, namely E. hilgendorfi Marcusen, 1894, E. stelliferum Calman, 1907, and E. latum Calman, 1907, all distributed in the IndoPacific from Japan to India. Kurian and Radhadevi
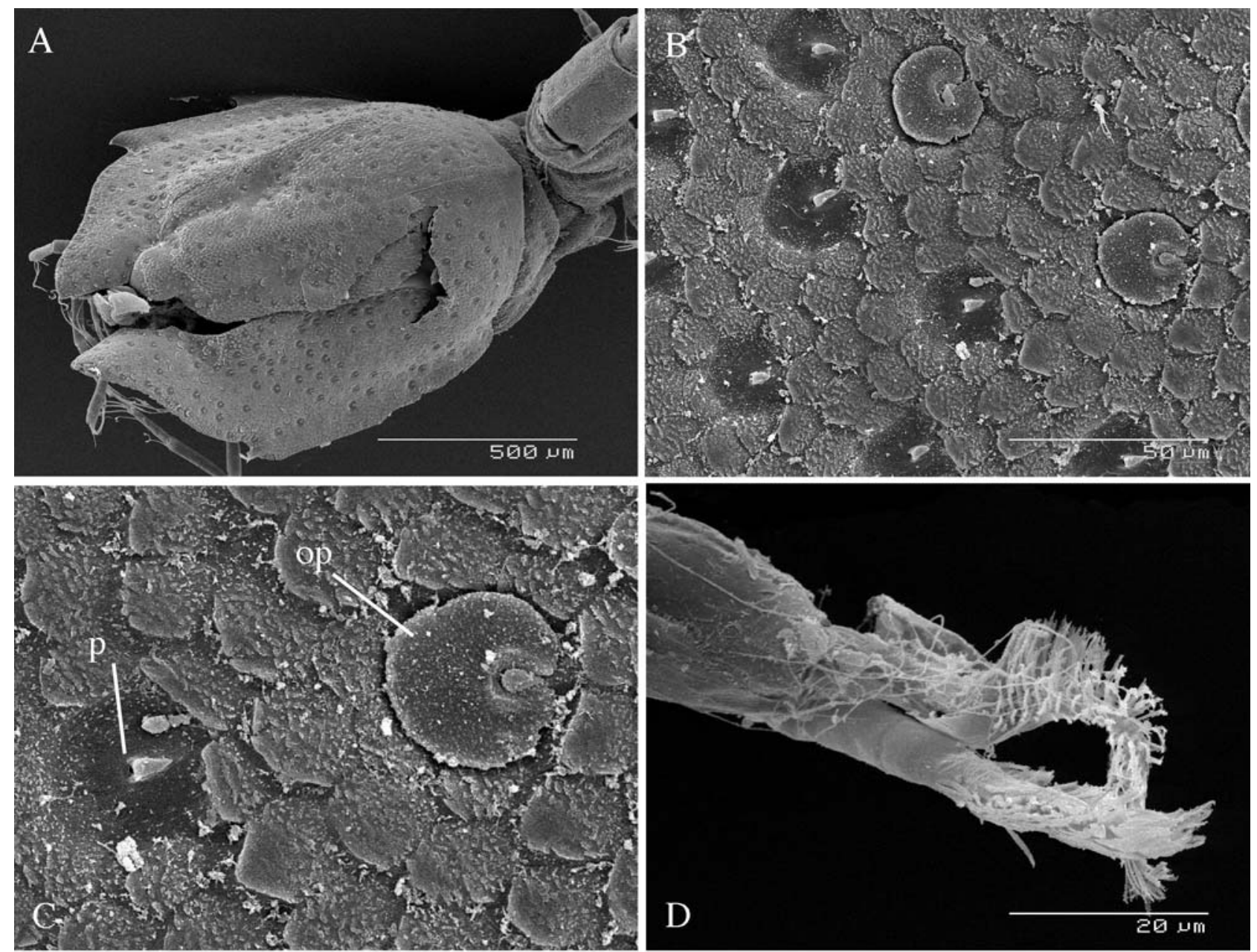

Fig. 3. - Eocuma rosae sp. nov., preadult female, SEM photographs: A, dorsal view of the carapace; B, close-up of the carapace cuticle where several sensory structures can be seen; C, detail of two sensory structures of B, one of them without the operculum (op) and showing the triangular projection where the operculum was attached and in front of it, a small pore (p); D, sensory setae at the tip of the uropod exopod. 


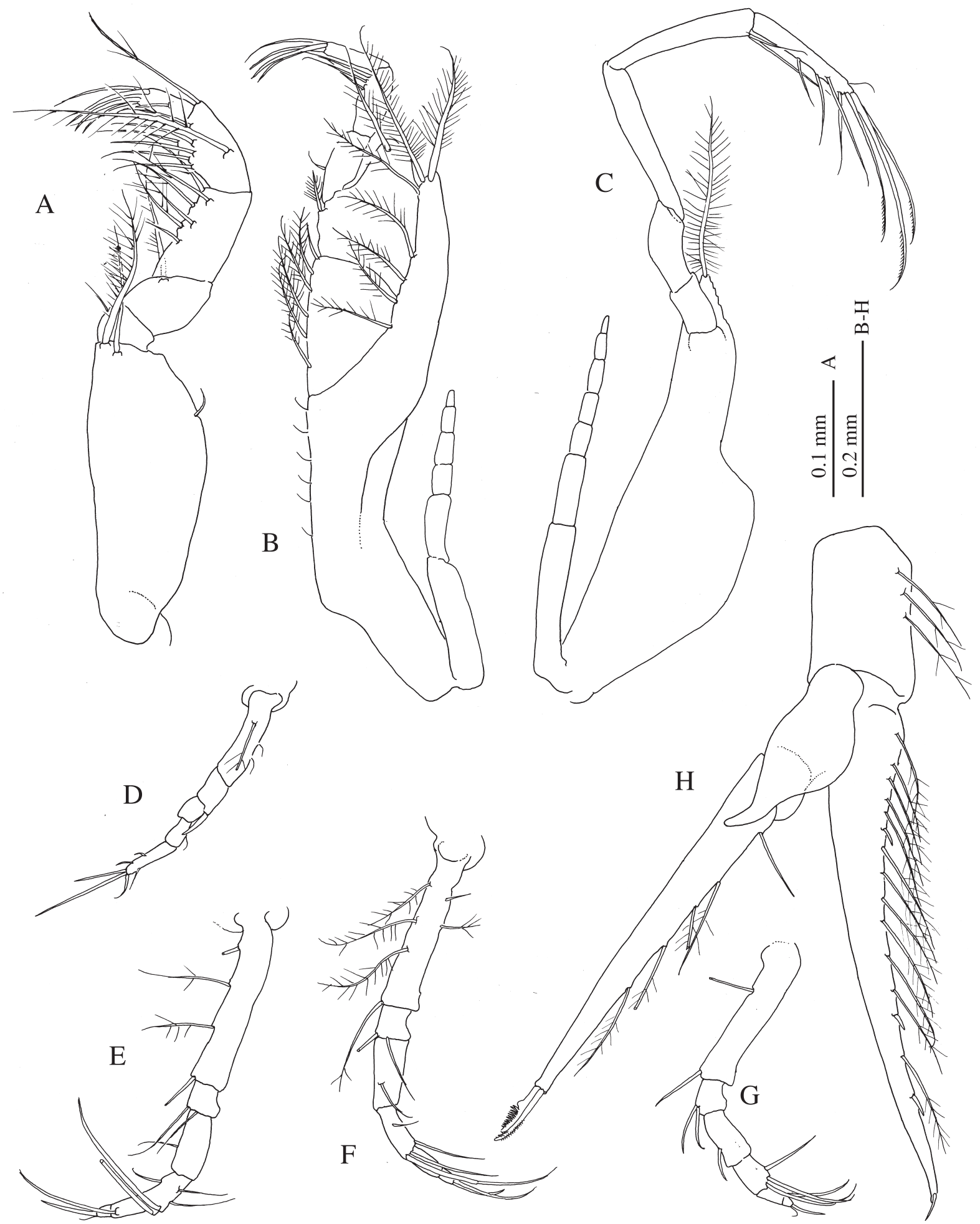

Fig. 4. - Eocuma rosae sp. nov., preadult female, paratype: A, maxilliped 2; B, maxilliped 3; C, pereopod 1; D, pereopod 2; E, pereopod 3; $\mathrm{F}$, pereopod 4; G, pereopod 5. Adult female, holotype: $\mathrm{H}$, left uropod.

(1983) described two additional species with the same features, E. striatum and E. sanguineum, from the coasts of India. Recently, Corbera et al. (2005) described another species from the Persian Gulf, $E$. carinocurvum. All these species have the anterolateral margin produced forward near the pseudorostrum, sometimes reaching its tip, forming an additional pair of projections. Eocuma rosae n. 
sp., as well as E. longicorne Calman, 1907, E. winri Day, 1978, E. bacescui Petrescu, 2003 and E. petrescui Patel et al., 2003 lack these projections, but the latter four species, although having the entire lateral margin of the carapace carinate, differ from E. rosae in lacking dorsolateral carinae on the carapace.

\section{DISCUSSION}

Although a high number of species (including fishes, crustacean decapods and molluscs) have invaded the Mediterranean Sea through the Suez Canal since its opening (Galil, 2000), no cumacean species have been included up to now in the long list of aliens.

Bacescu (1961) describing a new subspecies of Iphinoe crassipes Hansen, 1895, I. crassipes haifae, from the Israel coast suggested a possible invasion of this species through the Suez Canal. However, Corbera (1994) cast doubt on this hypothesis because the species was present off the northeastern coast of the Iberian Peninsula.

Conversely, there is no doubt on the geographical origin of the individuals of Scherocumella gurneyi found during this study in the Mediterranean. The species was described by Calman (1927) from the Gulf of Suez and Lake Timash (Suez Canal), and by Bacescu and Muradian (1975) from the Bitter Lakes and El Qantara (Suez Canal), as well as from the Gulf of Elat. Its presence along the northern Israeli coast clearly fits the pattern of expansion of Red Sea aliens into the Mediterranean (Galil, 2006).

Eocuma rosae n. sp. is closely related to a group of species from the Indo-Pacific Ocean (see above). It is probable that $E$. rosae was a so far unknown component of the Erythrean fauna, which recently colonised the Mediterranean Sea through the Suez Canal. This is not the first case in which a Red Sea crustacean species new to science has been described from the Mediterranean, where it is obviously an alien: Ixa monodi (Holthuis and Gottlieb, 1956) was described from material collected in the Bay of Mersin, southeastern Turkey, and Alpheus migrans (Lewinsohn and Holthuis, 1978) was described from specimens collected in the southeastern Levantine Basin.

Cumaceans lack a planktonic stage and their swimming abilities are restricted, so their capacity for dispersal is small. These are probably the main reasons why Red Sea cumaceans have not been found in the Mediterranean up to now. However, the great increase in the width and depth of the Canal, which has allowed faster currents (see Galil and Zenetos, 2002), together with the increase in water temperature in the Levant Sea due to global warming, could facilitate the entry of a larger number of Erythrean cumaceans into the Mediterranean.

\section{ACKNOWLEDGEMENTS}

B.G. thanks the Israel Ministries of Infrastructure and the Environment for funding the National Monitoring Programme, and Dr. B. Herut, for the coordination of the Programme. Dr. R. Fontarnau and collaborators are also thanked for their assistance during the SEM sessions in the Serveis Cientificotècnics - University of Barcelona.

\section{REFERENCES}

Bacescu, M. - 1961. Contributions a l'etude des cumacés de la Mediterranée et particulierment des côtes d'Israel. Rapp. VRe. CIESMM, 16: 459-502.

Bacescu, M. and Z. Muradian. - 1975. New Cumacea from the Red Sea. Trav. Mus. Hist. Nat. "Gr. Antipa”, 16: 35-69.

Bacescu, M. and I. Petrescu. - 1999. Ordre des Cumacés (Cumacea Krøyer 1846). In: J. Forest (ed.), Traité de Zoologie, Tome VII Fascicule IIIA Crustacés Péracarides. Mem. Inst. Océanogr., Monaco 19: 391-428.

Calman, W.T. - 1907. On new or rare Crustacea of the order Cumacea from the collection of the Copenhagen Museum. Part I. Trans. Zool. Soc. London, 18(1): 1-58.

Calman, W.T. - 1927. Report on the Phyllocarida, Cumacea and Stomatopoda (Cambridge Exp. Suez 1924). Trans. Zool. Soc. London, 22: 399-401.

Corbera, J. - 1994. A new record of Iphinoe crassipes Hansen, 1895 (Cumacea, Bodotriidae) from Catalonian coast. Sci. Mar., 58(3): 273-276.

Corbera, J., P. Tirado and D. Martin. - 2005. Cumaceans (Crustacea: Peracarida) from the Persian Gulf. Zootaxa, 1087: 1-37.

Day, J. - 1978. Southern African Cumacea. Part 2. Family Bodotriidae, Subfamily Bodotriinae. Ann. S. Afr. Mus., 75: 159-290.

Galil B.S. - 2000. Lessepsian immigration: human impact on Levantine biogeography. In: J.C. von Vaupel Klein and F.R. Schram (eds.), The biodiversity crisis and Crustacea, pp 47-54. AA Balkema, Rotterdam.

Galil, B.S. - 2006. The marine caravan - the Suez Canal and the Erythrean invasion. In: S. Gollasch, B.S. Galil and A. Cohen (eds.), Bridging divides. Kluwer Academic Publishers, Dordrecht.

Galil B.S. and A. Zenetos. - 2002. A sea change - Exotics in the eastern Mediterranean. In: E. Leppakoski, S. Gollasch and S. Olenin (eds.), Invasive Aquatic Species of Europe. Distribution, Impacts and Management, pp. 325-336. Kluwer Academic Publishers, Dordrecht.

Goren, M. and B.S. Galil. - 2005, A review of changes in the fish assemblages of Levantine inland and marine ecosystems following the introduction of non-native fishes. J. Appl. Ichthyol., 21(4): 364-370.

Hansen, H.J. - 1895. Isopoden, Cumaceen und Stomatopoden der Plankton-Expedition. Ergebn. Plankton-Exped. 2: 1-105.

Holthuis, L.B. and E. Gottlieb. - 1956. Two interesting crabs (Crustacea Decapoda, Brachyura) from Mersin Bay, SE Turkey. Zool. Meded., Leiden, 34: 287-299. 
Kurian, C.V. and A. Radhadevi. - 1983. A new species of Cumacea (Crustacea, Peracarida) from Vizhinjom, Kerala, India. In: P. Rabindranath (ed.), Selected Papers on Crustacea, pp. 149-153. The Aquarium, Trivandrum.

Lewinsohn, C. and L.B. Holthuis. - 1978. On a new species of Alpheus (Crustacea, Decapoda, Natantia) from the Eastern Mediterranean. Zool. Meded., Leiden, 53(7): 75-82.

Patel, C.K., P.A. Haye and I. Kornfield. - 2003. Eocuma petrescui, a new species of bodotriid cumacean (Crustacea; Peracarida) from Malaysia. Proc. Biol. Soc. Washington, 116: 978-985.

Petrescu, I. - 2003. First record of Cumacea (Crustacea: Peracarida) from Madagascar. Trav. Mus. Nat. Hist. Nat. "Gr. Antipa”, 45: 95-115.
Sars, G.O. - 1979. Middlehavets Cumaceer. Arch. Math. Natur., 4: $1-144$.

Watling, L. - 1991. Rediagnosis and revision of some Nannastacidae (Crustacea: Cumacea). Proc. Biol. Soc. Wash., 104(4): 751-757.

Zibrowius, H. - 1992. Ongoing modification of the Mediterranean marine fauna and flora by the establishment of exotic species. Mésogée, 51: 83-107.

Scient. ed.: P. Abelló

Received June 12, 2006. Accepted October 9, 2006.

Published online January 23, 2007. 